\title{
Twelve tips for implementing whole-task curricula: How to make it work
}

Citation for published version (APA):

Dolmans, D. H. J. M., Wolfhagen, I. H. A. P., \& Van Merrienboer, J. J. G. (2013). Twelve tips for implementing whole-task curricula: How to make it work. Medical Teacher, 35(10), 801-805. https://doi.org/10.3109/0142159X.2013.799640

Document status and date:

Published: 01/01/2013

DOI:

10.3109/0142159X.2013.799640

Document Version:

Publisher's PDF, also known as Version of record

Document license:

Taverne

Please check the document version of this publication:

- A submitted manuscript is the version of the article upon submission and before peer-review. There can be important differences between the submitted version and the official published version of record.

People interested in the research are advised to contact the author for the final version of the publication, or visit the DOI to the publisher's website.

- The final author version and the galley proof are versions of the publication after peer review.

- The final published version features the final layout of the paper including the volume, issue and page numbers.

Link to publication

\footnotetext{
General rights rights.

- You may freely distribute the URL identifying the publication in the public portal. please follow below link for the End User Agreement:

www.umlib.nl/taverne-license

Take down policy

If you believe that this document breaches copyright please contact us at:

repository@maastrichtuniversity.nl

providing details and we will investigate your claim.
}

Copyright and moral rights for the publications made accessible in the public portal are retained by the authors and/or other copyright owners and it is a condition of accessing publications that users recognise and abide by the legal requirements associated with these

- Users may download and print one copy of any publication from the public portal for the purpose of private study or research.

- You may not further distribute the material or use it for any profit-making activity or commercial gain

If the publication is distributed under the terms of Article $25 \mathrm{fa}$ of the Dutch Copyright Act, indicated by the "Taverne" license above, 


\title{
Medical Teacher
}

\section{Twelve tips for implementing whole-task curricula: How to make it work}

\author{
Diana H.J.M. Dolmans, Ineke H.A.P. Wolfhagen \& Jeroen J.G. Van Merriënboer
}

To cite this article: Diana H.J.M. Dolmans, Ineke H.A.P. Wolfhagen \& Jeroen J.G. Van Merriënboer (2013) Twelve tips for implementing whole-task curricula: How to make it work, Medical Teacher, 35:10, 801-805, DOI: 10.3109/0142159X.2013.799640

To link to this article: https://doi.org/10.3109/0142159X.2013.799640

曲 Published online: 19 Jun 2013.

Submit your article to this journal ¿

Џll Article views: 1567

Q View related articles $\asymp$

4 Citing articles: 7 View citing articles 진 


\title{
Twelve tips for implementing whole-task curricula: How to make it work
}

\author{
DIANA H.J.M. DOLMANS, INEKE H.A.P. WOLFHAGEN \& JEROEN J.G. VAN MERRIËNBOER \\ Maastricht University, School of Health Professions Education (SHE), The Netherlands
}

\begin{abstract}
Whole-task models of learning and instructional design, such as problem-based learning, are nowadays very popular. Schools regularly encounter large problems when they implement whole-task curricula. The main aim of this article is to provide 12 tips that may help to make the implementation of a whole-task curriculum successful. Implementing whole-task curricula fails when the implementation is not well prepared. Requirements that must be met to make the implementation of whole task models into a success are described as twelve tips. The tips are organized in four clusters and refer to (1) the infrastructure, (2) the teachers, (3) the students, and (4) the management of the educational organization. Finally, the presented framework will be critically discussed and the importance of shared values and a change of culture is emphasized.
\end{abstract}

\section{Introduction}

In the 21st century, there has been a growing interest in wholetask models of learning and instructional design. Such models stress that meaningful student learning is best driven by 'whole' learning tasks (e.g., problems, cases, projects) that are preferably based on real-life or professional tasks (van Merrienboer \& Kester 2008). They include various approaches such as problem-based learning (Wood 2003), project-based learning (Wessell \& Spreckelsen 2009), team-based learning (Parmelee et al. 2012), the Harvard case-method (DeMarco et al. 2002), competence-based learning (Gudrun 2006), and several other models (for an overview, see Merrill 2012). The popularity of whole-task models is a reaction to traditional part-task models, which analyze a complex learning domain into smaller pieces and then teach the domain piece-by-piece, often leaving the learners with a fragmented view on the domain. In contrast, whole-task models analyze a learning domain as a coherent, integrated whole and then teach it from relatively simple, yet meaningful whole tasks that are representative for the whole domain to increasingly more complex whole tasks.

There is accumulating evidence for the effectiveness, efficiency and appeal of whole-task models in education (Norman \& Schmidt 2000; Gijbels et al. 2005; Van Merriënboer \& Kester 2008; Merrill 2012). Yet, schools and universities regularly encounter large problems when they are trying to implement whole-task curricula. Failure to bring this process of educational innovation to a good end is not uncommon (Lazerson 2000). The main aim of this article is to provide 12 tips that may help to make the implementation of a whole-task curriculum successful. Although some of these tips are based on the available literature, they are also rooted in the authors' personal experiences because their School of Health
Professions Education has ample experience with advising schools on the innovation of educational processes through the implementation of whole-task curricula. The structure of this article is as follows. First, the main characteristics of wholetask models will be described in more detail. Second, requirements that must be met to make the implementation of whole task models into a success are described as twelve tips. Finally, the presented framework will be critically discussed and the importance of shared values and a change of culture is emphasized.

\section{Whole-task models for curriculum design}

In their Ten Steps to Complex Learning, van Merriënboer and Kirschner (2013) describe a systematic approach to the development of whole-task curricula. Obviously, this process starts with the development of whole tasks that will be provided to the students, such as problems, cases, projects or other whole tasks that serve as the backbone of the educational program. Requirements to these whole tasks concern their authenticity, variability, increase in complexity, and decrease in provided support and guidance.

First, whole tasks are preferably based on real-life, authentic professional tasks because this will help students acquire knowledge, skills and attitudes in an integrated fashion. Second, the whole tasks in the curriculum should be different from each other on all dimensions on which real-life tasks are also different from each other, because this "variability of practice' will help transfer of learning. Third, the whole tasks need to be sequenced throughout the curriculum from relatively simple tasks that are, ideally, yet representative for the simplest tasks a professional could encounter in the

Correspondence: Diana H.J.M. Dolmans, Maastricht University, Department of Educational Development and Research, School of Health Professions Education, SHE, Faculty of Health, Medicine and Life Sciences, FHML, PO Box 616, 6200 MD, Maastricht, The Netherlands. Tel:00 31 43 388 5730; email: D.Dolmans@maastrichtuniversity.nl 


\section{Characteristics}

Authentic professional whole tasks are the backbone Variability in whole tasks

From simple to increasingly more complex tasks

Decrease in provided support and guidance at each level of complexity

Supportive information (books, lectures)

Skills training integrated in whole tasks

Longitudinal monitoring of student progress (e.g., a portfolio)

\section{Reason}

Integrated application of knowledge, skills and attitudes Transfer of learning

Continuous professional development

Independent performance

Theory to acquire knowledge

Practice procedural skills

Integrated assessment of knowledge, skills and attitudes domain, to increasingly more complex tasks until the level of complexity is reached that a beginning professional must be able to handle. Finally, for tasks at a particular level of complexity, students first need ample support and guidance from their teacher or instructional materials but this support and guidance will diminish in a process of 'scaffolding' (Pea 2004) until students are able to independently perform the tasks at this level of complexity without any support or guidance; thereafter, they can continue with tasks at a higher level of complexity. This is also known as a 'spiral' curriculum (Bruner 1960).

The sequence of authentic and variable whole tasks, ordered from simple to complex and with decreasing support and guidance at each level of complexity, can be seen as the backbone of a typical whole-task curriculum. Whole-task models claim that all other educational components must be logically connected to this backbone in order to realize an integrated curriculum (Janssen-Noordman et al. 2006). A first component concerns the supportive information or the 'theory' that students need to work on the whole tasks. For example, in a problem-based curriculum these will be the resources (books, websites, videos etc.) that students can consult in a 'study landscape' to come up with explanations for the problem/s they have been discussing in their educational group, or in a project-based curriculum these will be the resources and lectures that provide students with the information they need to properly conduct their project/s. Another component concerns the procedural skills that students need to develop to a very high level of automaticity. For example, in a problem-based medical curriculum technical skills such as clinical examination and invasive procedures may be practiced in a skills laboratory (skillslab) by the time they are introduced in a whole-task problem. Finally, assessment in a whole-task curriculum will also be different from that in a traditional curriculum. In a traditional curriculum, each 'part' (e.g., course, discipline) of the curriculum can be separately assessed and certification takes place after all parts have been assessed with good results. This is not true in a whole-task curriculum because the backbone of simple-to-complex whole learning tasks requires an assessment system in which knowledge, skills and attitudes are preferably assessed in an integrated fashion in a simulated or real professional environment and in which the progress each student is making is monitored by teachers and students themselves. For example, development portfolios can be used to gather assessment results for wholetasks that students have performed, keep track of student progress, and make it possible to provide feedback on past performance (Van Merrienboer \& van der Vleuten 2012). 802
In Table 1, the main characteristics of a whole-task curriculum are summarized.

\section{Requirements to implementation}

Whole-task curricula offer students a continuous learning trajectory based on whole learning tasks, connect all other educational components to this trajectory, and systematically assess student progress. Things easily go wrong in the implementation of whole-task curricula. This section identifies the main pitfalls and discusses tips that may help to make the innovation work. The tips are organized in four clusters and refer to (1) the available infrastructure, (2) the teachers, (3) the students, and (4) the management of the educational organization.

\section{Infrastructure}

\section{Tip 1}

\section{Redesign your building}

The organizing units in a whole-task curriculum are whole learning tasks rather than lectures. Students typically work on those learning tasks in small groups, for example, groups of 610 students in problem-based learning or teams from 5-7 students in team-based learning. Thus, you would need smallgroup rooms rather than large lecture rooms to schedule the main part of the educational meetings. And these rooms should be well equipped to support group work, with a whiteboard, projection facilities and wireless Internet access. This is not to say that other facilities such as lecture rooms, library study places and skill/simulation laboratories are no longer necessary, but the balance between small-group rooms and traditional lecture rooms will drastically change. This needs to be planned well in advance.

\section{Tip 2}

\section{Prepare instructional materials}

The main instructional materials in a whole-task curriculum are problems, projects, cases or other types of whole tasks rather than traditional study books, readers and lectures. For the majority of programs, these instructional materials describing the whole tasks will not be readily available but must be designed and constructed by teachers, and even when 
materials from other programs can be used, it will typically be necessary to adjust these materials to the specific context and student population. In addition, the whole tasks will often not only be offered as written text in 'blockbooks' or case books, but may also take the form of simulated or computer-simulated task environments in which students work on the tasks. For example, one might think of simulated patient cases or electronic virtual patients (Huwendiek et al. 2009) in a medical curriculum. The development of interesting whole tasks is a difficult and time-consuming activity which should not be underestimated.

\section{Tip 3}

\section{Reform the assessment and implement a monitoring system}

Some curricular innovators decide to adapt the assessment later on. Since we know that assessment drives learning, it is crucial to also reform the assessment when redesigning the curriculum. An important assessment instrument in a wholetask curriculum should allow for the monitoring of individual student progress, rather than for only making pass/fail decisions for separate courses. The responsibility for the development, use and evaluation of such a monitoring system is at the level of the whole curriculum, and can never be taken by one or more individual teachers. For example, the development and implementation of an electronic development portfolio is complex, because it requires the regular gathering and storing of assessment results and the disposal of a 'dashboard' that informs both individual students and their teachers on progress and points of improvement.

\section{Teachers}

\section{Tip 4}

\section{Select teachers working in the profession}

Whole-task curricula emphasize the importance of introducing learners to professionally relevant tasks; problems, cases or other types of whole tasks. Designing tasks that are professionally relevant, can of course best be done by professionals working in the profession. In a whole-task medical curriculum, practicing physicians play a dominant role in the design and delivery of the curriculum, since they know what is relevant to learn when working in the profession. These professionals need training in how to design learning tasks. Furthermore, educationalists with expertise on development of curricula and instructional design as well as students should be involved in the design of whole-task curricula.

\section{Tip 5}

\section{Prepare and train teachers to fulfill different teaching} roles

Teachers within whole-task curricula fulfill different teaching roles; i.e. they play a role in the design of tasks, facilitate small group learning, facilitate skills training sessions, etc. Most teachers or professionals might not be familiar with these new teaching roles. In order to clearly define responsibilities it should be described which activities should be done within the different roles and what the formal requirements are, e.g., a course coordinator is responsible for the design, implementation and evaluation of a course, delegating the work among the multidisciplinary team of staff members who will design the course, must have attended mandatory training, be a good tutor, etc. Furthermore, it is crucial to prepare and train staff members to fulfill these roles. Many schools nowadays have a faculty development program to prepare their staff members. Especially practicing clinicians need training to fulfill these teaching roles since they often have had limited teaching training. Preferably not short single training activities are offered, but courses that extent over a period of time, since these latter are known to be more effective (Stes et al. 2010). These faculty development programs have positive effects in terms of acquiring teaching skills both from the perceptions of the training participants, especially training courses in which experiential learning, feedback and relationship building with colleagues are included (Steinert et al. 2006).

\section{Tip 6}

\section{Make teachers work together in multi-disciplinary teams of professionals}

When every teacher would individually implement a wholetask curriculum, it will be very difficult to design a well aligned curriculum in which professionally relevant and multidisciplinary tasks are the main backbone of the curriculum. As a consequence, learning tasks are designed by teams of teachers from different disciplines in whole-task curricula. Collaboration among teachers from different disciplines when designing tasks is not easy, since many professionals are more used towards disciplinary thinking than multi-disciplinary thinking. Often professionals believe their own discipline to be the first and most important discipline. To reduce disciplinary thinking and encourage multi-disciplinary thinking, teachers preferably work together in multi-disciplinary teams when designing the curriculum. Which disciplines should be involved in the design per course is specified in a blueprint of the curriculum; a document in which it is globally stated which learning tasks are covered in the specific courses and which disciplines are involved in a specific course.

\section{Students}

\section{Tip 7}

Involve students in the preparation of the planning, design and evaluation of the curriculum

Students can play an important role in planning, designing and evaluating a whole-task curriculum. Since students know how the curriculum works in daily practice, they can give valuable insights in the curriculum's strengths and weaknesses. 
Involve students in the curriculum planning committee, since students can explain why it is needed to change the curriculum; they can become advocates of the new approach. Students should also be a member of the multidisciplinary teams of teachers responsible for designing a course. A whole task will only be effective and promote learning if it is perceived by students as a meaningful and interesting task. Thus, within the course development teams students can be asked to give feedback on the whole tasks that are designed, and also on the literature to be studied, etc. Furthermore, students can play a role in evaluating the curriculum.

\section{Tip 8}

\section{Explain the ideas behind the innovative whole-task approach to students}

It is important that students have knowledge about the ideas behind the innovative whole-task approach and are wellinformed. Knowledge about the ideas behind the innovative approach can help students to obtain insight in why they are expected to work on whole tasks and integrate knowledge, skills and attitudes, why they are encouraged to apply what they have learnt to various problems, and what the advantages are of the new approach. This knowledge will help to create shared beliefs about the new approach.

\section{Tip 9}

\section{Prepare and train students to fulfill different student roles}

Students in a whole-task curriculum will fulfill different roles since they will work in small groups. As a consequence, students need to be prepared to lead a discussion group, to give and receive feedback in a small group, to fulfill the role of scribe in a group, but also how to actively contribute as a group member and how to prepare for a group meeting. Providing students with information and knowledge is not sufficient, students also need to be trained to fulfill these different roles, since students might be less familiar with some roles. Student preparation is often neglected or limited to short one-time training sessions at the start of the first year, whereas these trainings preferably take place longitudinally.

\section{The management of the educational organization}

\section{Tip 10}

\section{Introduce central management}

As argued before, if every teacher would have full freedom to design parts of the curriculum, it would be impossible to design a coherent, integrated and well aligned whole-task curriculum. A strong central management is needed to reduce the autonomy of individual teachers and individual disciplines. But, how to organize central management? And, how to organize teams of multidisciplinary professionals? A central management often consists of an educational director together with two or three coordinators who are responsible for specific parts of a curriculum; e.g., a bachelor coordinator and a master coordinator or for each year a coordinator. This central management delegates responsibilities to multidisciplinary teams of teachers. These teams are responsible for designing, implementing and evaluating different parts of the curriculum; the different courses. The director and the management team must have authority and mandates within the organization and communicate well with all bodies within the organization. The management appoints course directors and decides which disciplines should be involved in the different teams that are responsible for designing courses. The selection of staff members per team can be done by the central management, but it is also possible that course coordinators suggest with whom they prefer to collaborate.

\section{Tip 11}

\section{Introduce systems to monitor educational quality and teacher performance}

Systems to monitor educational quality and teacher performance are crucial to deliver a high quality whole-task curriculum that is continuously improved. Quality assurance systems need to be in place that provide insight in those aspects of the curriculum that need improvement, both at the curriculum and course level, but also at the teacher level. The curriculum should be evaluated based on various data sources, assessment data, evaluative data at the curriculum, course and teacher level, but also a regular evaluation of the contents offered in the curriculum; e.g., by means of a curriculumcontents data-base. These evaluations should result in actions for improvement and it is important to monitor whether these actions result in improvements. But, it is also important that there is a policy or system for rewarding educational performance. Education should play a role in the career of teachers. A strong human resource management is needed (Bland et al. 2000).

\section{Tip 12}

\section{Provide educational support}

From the description above it becomes clear that a whole-task curriculum puts high demands on designing, maintaining and evaluating a curriculum. Professionals who play a dominant role within this curriculum need support in the area of faculty development, information and communication technology, assessment, and quality assurance. Faculty development courses must be developed, curriculum materials must be developed that increase in fidelity level (e.g., paper problems, simulations, real problems), the assessment must be reformed and the quality of the curriculum and the teachers must be evaluated and monitored. This expertise is often offered by educational department units in which both educationalists and professionals have expertise on these areas of educational support. It is important that these experts make use of scientific insights in these areas and are well aware of the literature in 
these areas, since curriculum innovations are preferably based on education research.

\section{Discussion and conclusion}

The tips above make it clear that implementing a whole-task curriculum can succeed when the innovation is well prepared. Teachers and students must be adequately prepared and an adequate infrastructure and organization is needed. However, not only organizational changes are required, but also cultural changes. Management elements are needed to coordinate activities, but shared values and beliefs are crucial as well for a successful curriculum innovation. An organizational culture or collective responsibility is needed that intends to deliver a high quality curriculum (EUA 2006). A culture is needed in which teachers and the management communicate with each other in an open atmosphere, in which teams members collaborate and feel jointly responsible, in which teachers connect with students. Furthermore, an appropriate balance between central management and autonomy of professionals or between a top-down and bottom-up approach is crucial.

Declaration of interest: The authors report no conflicts of interest.

\section{Notes on contributors}

DIANA H.J.M. DOLMANS, PhD, is a Professor of Innovative Learning Arrangements, staff member of the School of Health Professions Education (SHE) at Maastricht University, The Netherlands.

INEKE HAP WOLFHAGEN, PhD, is an associate professor, staff member of the School of Health Professions Education (SHE) at Maastricht University, The Netherlands.

JEROEN VAN MERRIËNBOER, PhD, is a Professor of Learning and Instruction, the research director of the School of Health Professions Education (SHE) at Maastricht University, The Netherlands.

\section{References}

Bland CJ, Starnaman S, Wersal L, Moorhead-Rosenberg L, Zonia S, Henry R. 2000. Curricular change in medical schools: How to succeed. Acad Med 75(6):575-594.

Bruner JS. 1960. The process of education. Cambridge, MA: Harvard University Press.

Demarco R, Hayward L, Lynch M. 2002. Nursing students' experiences with and strategic approaches to case-based instruction: A replication and comparison study between two disciplines. J Nurs Educ 41(4):165-174.
EUA, European University Association. 2006. Quality culture in European universities: A bottom-up approach, Report on the three rounds of the quality culture project 2002-2006. Brussels: EUA.

Freeman A, van der Vleuten C, Nouns Z, Ricketts C. 2010. Progress testing internationally. Medical Teacher 32:451-455

Gijbels D, Dochy F, Van den Bossche P, Segers M. 2005. Effects of problembased learning: A meta-analysis from the angle of assessment. Rev Educ Res 75(1):27-61.

Gudrun E. 2006. Developing a competence-based core curriculum in biomedical laboratory science: A Delphi study. Med Teacher 28:409-417.

Huwendiek S, de Leng BA, Zary N, Fischer MR, Ruiz JG, Ellaway R. 2009. Towards a typology of virtual patients. Med Teacher 31:743-748.

Janssen-Noordman AMB, van Merriënboer JJG, van der Vleuten CPM, Scherpbier AJJA. 2006. Design of integrated practice for learning professional competences. Med Teacher 28(5):447-452.

Lazerson M. 2000. What makes a revolution? Teaching and learning in higher education, 1980-2000. Change 32:12-19.

Merrill MD. 2012. First principles of instruction. Pfeiffer: John Wiley and Sons.

Norman GR, Schmidt HG. 2000. Effectiveness of problem-based learning curricula: Theory, practice and paper darts. Med Educ 34:721-728.

Parmelee D, Michaelsen LK, Cook S, Hudes PD. 2012. Team-based learning: A practical guide: AMEE Guide No. 65. Med Teacher $34: \mathrm{e} 275-287$.

Pea R. 2004. The social and technological dimensions of scaffolding and related theoretical concepts for learning, education, and human activity. J Learn Sci 13:423-451.

Steinert Y, Mann K, Centeno A, Dolmans D, Spencer J, Gelula M, Prideaux D. 2006. A systematic review of faculty development initiatives designed to improve teaching effectiveness in medical education: BEME guide no 8. Medical Teacher, 28(6):497-526.

Stes A, Min-Leliveld M, Gijbels D, Van Petegem P. 2010. The impact of instructional development in higher education: The state-of-the art of the research. Educ Res Rev 5:25-49.

Van Merriënboer JJG, Kester L. 2008. Whole-task models in education. In: Spector JM, Merrill MD, van Merriënboer JJG, Driscoll MP, editors. Handbook of research on educational communications and technology. Third ed. Mahwah, NJ: Erlbaum/Routledge. pp 441-456.

Van Merrienboer JJG, Kirschner PA. 2013. Ten steps to complex learning. 2nd Rev. ed. New York: Routledge.

Van Merrienboer JJG, van der Vleuten CPM. 2012. Technology-based assessment in the integrated curriculum. In: Mayrath MC, ClarkeMiruda J, Robinson DH, Schraw G, editors. Technology-based assessments for 21st century skills. Charlotte, NC: Information Age Publishing. pp 345-370.

Wessels C, Spreckelsen C. 2009. Continued multidisciplinary project-based learning: Implementation in health informatics. Meth Informat Med 48:558-563.

Wood DF. 2003. ABC of learning and teaching in medicine: Problem-based learning. Br Med J 326:328-330. 